\title{
PERSPECTIVAS (TEÓRICO)-METODOLÓGICAS PARA O CAMPO DA PESQUISA EM EDUCAÇÃO AMBIENTAL: DILEMAS E AVANÇOS NO GDP METODOLOGIA
}

\author{
Clarice Sumi Kawasaki ${ }^{1}$ \\ Marcos da Cunha Teixeira ${ }^{2}$
}

\begin{abstract}
Resumo
Analisam-se as perspectivas teórico-metodológicas dos trabalhos apresentados nos Encontros de Pesquisa em Educação Ambiental (EPEA). Estas partem dos olhares e vivências dos coordenadores dos Grupos de Discussão em Pesquisa (GDP Metodologia) junto às discussões realizadas nesses grupos, cujos relatos encontram-se na forma de produções textuais, identificando-se os pontos limitantes e as potencialidades do campo metodológico da pesquisa em educação ambiental ao longo dos EPEAs. Em meio à multirreferencialidade de perspectivas presentes nesses trabalhos, problemas de natureza epistemológico-metodológica são identificados, principalmente em função de uma forte tendência em atrelar as escolhas metodológicas dos investigadores a uma pesquisa voltada para a transformação social e às perspectivas críticas e metodologias participativas como as abordagens metodológicas que melhor responderiam a essa tendência. Os dilemas envolvidos e as implicações disso para as discussões teórico-metodológicas no campo da pesquisa em EA são discutidos, trazendo avanços para as discussões no GDP Metodologia. Para além dessas questões, uma pesquisa subversiva, em consonância com uma EA subversiva, se avizinha no horizonte, trazendo novas discussões para esse cenário.
\end{abstract}

Palavras-chave: Perspectivas Metodológicas. Pesquisa em Educação Ambiental. Transformação Social. Metodologias Críticas e Participativas.

\section{PERSPECTIVES (THEORETICAL)-METHODOLOGICAL FOR THE FIELD OF RESEARCH IN ENVIRONMENTAL EDUCATION: DILEMMAS AND ADVANCES IN THE GDP METHODOLOGY}

\begin{abstract}
The theoretical-methodological perspectives present in the papers presented at the Environmental Education Research Meetings (EERM) are analyzed. The perspectives are based on the views and experiences of the Coordinators of the Research Groups (GDP Methodology) and the discussions carried out in these groups, whose reports are textual productions that identify the limiting points and the potentialities of the methodological area of research in environmental education throughout the EPEAs.The problems of the epistemological-methodological type are identified amid the multi-referentiality of perspectives present in these papers, mainly due to the strong tendency to combine the methodological choices of the researchers with a research focused on social transformation and critical perspectives and participatory methodologies, such as methodological approaches which would best answer this trend. The dilemmas involved in the research and their implications for theoretical-methodological discussions in the EA research area are discussed, bringing advances to discussions in the GDP Methodology. In addition to these issues, a
\end{abstract}

\footnotetext{
${ }^{1}$ Professor Doutor na FFCLRP/USP. Email: sumi @ffclrp.usp.br

${ }^{2}$ Professor Adjunto da UFES. Email: marcosteixeiraufes@gmail.com
} 
subversive research, in line with an equally subversive EA, can already be seen on the horizon, bringing new discussions to this scene.

keywords

Keywords: Methodological Perspectives. Research in Environmental Education. Social Transformation. Critical and Participatory Methodologies.

\section{PERSPECTIVAS (TEÓRICO) METODOLÓGICAS PARA EL CAMPO DE LA INVESTIGACIÓN EN EDUCACIÓN AMBIENTAL: DILEMAS Y AVANCES EN EL GDP METODOLOGÍA}

\section{Resumen}

Se analizan las perspectivas teórico-metodológicas de los trabajos presentados en los Encuentros de Investigación en Educación Ambiental (EPEA), las cuales son definidas por las miradas y vivencias de los coordinadores de los Grupos de Discusión en Pesquisa (GDP Metodología) junto a las discusiones realizadas en esos grupos, cuyos relatos se encuentran en forma de producciones textuales, identificando los puntos limitantes y las potencialidades del campo metodológico de la investigación en educación ambiental a lo largo de los EPEA. En medio de la multi-referencialidad de perspectivas presentes en esos trabajos, se identifican problemas de naturaleza epistemo-metodológica, principalmente en función de una fuerte tendencia a atar las elecciones metodológicas de los investigadores a una investigación volcada hacia la transformación social ya las perspectivas críticas y metodologías participativas como los enfoques metodológicos que mejor respondan a esta tendencia. Los dilemas involucrados y las implicaciones de ello para las discusiones teórico-metodológicas en el campo de la investigación en EA se discuten, trayendo avances para las discusiones en el GDP Metodología. Además de estas cuestiones, una investigación subversiva, en consonancia con una EA subversiva, se avecina en el horizonte, trayendo nuevas discusiones para ese escenario.

Palabras clave: Perspectivas Metodológicas. Pesquisa en Educación Ambiental. Transformación Social. Metodologías Críticas y Participativas.

\section{Introdução}

Que questões relacionadas com as perspectivas metodológicas têm sido colocadas nos atuais debates sobre a pesquisa em Educação Ambiental? Essas poderiam ser discutidas de forma específica ou independente das questões epistemológicas que as embasam e dão suporte?

Tais questionamentos são postos como pontos de partida para sistematizar e fazer reflexões a partir das discussões feitas nos encontros do GDP Pesquisa em Educação Ambiental e Questões Metodológicas (GDP Metodologia) nos Encontros de Pesquisa em Educação Ambiental (EPEA), dentre elas, uma discussão acerca da pertinência, ou não, de um Grupo de Discussão de Pesquisa (GDP) específico para as questões metodológicas nesses encontros.

Os GDPs são espaços de discussão das pesquisas apresentadas nesse evento, as quais estão articuladas a determinados eixos temáticos propostos pela organização. Dentre eles, há o referido GDP Metodologia, que surge em meio a discussões feitas no GDP Pesquisa em EA e Questões Epistemológicas ou GDP Epistemologia, durante o III EPEA, em 2005, onde os aspectos metodológicos passaram a ocupar um espaço significativo nessas discussões. Isso 
levou a organização do evento a avaliar se, estrategicamente, não seria interessante dissociálas desse grupo, criando espaços específicos que permitissem seu aprofundamento. Foi nesse contexto que se criou, no VI EPEA, em 2011, o GDP Metodologia, estando, hoje, em sua $4^{\text {a }}$ edição.

Porém, no decorrer das discussões feitas no interior dos GDPs Metodologia, realizados nos EPEAs, as quais estão relatadas em produções textuais produzidas a partir dessas experiências (FERNANDES; KAWASAKI, 2012; TOZONI-REIS; SOUZA， 2014; TOZONI-REIS; KAWASAKI, 2016), tal projeção não se desenvolveu conforme o esperado, pois problemas de natureza teórico-prática, encontrados nesse processo, inviabilizaram o aprofundamento das questões metodológicas da pesquisa em EA.

Este artigo busca fazer uma revisão crítica dessas discussões, retomando os relatos anteriores desse GDP e analisando a experiência de sua última edição no IX EPEA, realizado em 2017, a fim de trazer os principais impasses e dilemas encontrados, bem como, os possíveis encaminhamentos para a superação desses problemas. Espera-se que, com isso, se possa dar um passo à frente, aprofundando as questões teórico-metodológicas da pesquisa em EA, tão almejadas na constituição inicial do GDP Metodologia.

\section{Reflexões sobre os relatos feitos a partir das experiências vivenciadas nos GDPs Metodologia}

Fernandes e Kawasaki (2012), na coordenação da $1^{\text {a }}$ edição do GDP Metodologia, no VI EPEA, em 2011, se depararam com uma multiplicidade de abordagens metodológicas na pesquisa em EA, o que a princípio veio reforçar a necessidade de um GDP específico para tais discussões. Em um mapeamento inicial, os coordenadores procuraram entender as motivações que levaram os participantes a esse GDP e suas principais questões metodológicas. Em virtude de ser um grupo de iniciantes na pesquisa em questão e ainda com pouca experiência na área, as motivações giraram em torno de uma busca individual por algum método para a sua própria pesquisa ou uma melhor compreensão acerca de metodologias e referenciais teórico-metodológicos presentes nessa área.

Em seguida, os coordenadores passaram a desenvolver uma dinâmica que possibilitasse aos participantes exercitar um olhar para o conjunto de 88 trabalhos aprovados no VI EPEA do ponto de vista das opções metodológicas contidas nesses trabalhos. Nessa, o grupo de participantes analisou as características dos trabalhos quanto à sua natureza, instrumentos, sujeitos, contextos e temas de pesquisa, reafirmando a presença, na área, de uma multiplicidade de abordagens metodológicas, destacando-se a predominância da abordagem qualitativa nessas pesquisas e o crescimento de pesquisas documentais, principalmente de estudos do tipo estado da arte, que apontam para a importância de se mapear e entender o campo da pesquisa em questão.

Pela análise sistematizada por esses participantes, pode-se identificar um aumento significativo da temática das políticas públicas específicas em EA, com forte ênfase em uma pesquisa voltada para a transformação social. Tais resultados geraram poucas discussões no grupo, ficando, muito mais, no esclarecimento acerca dessas perspectivas metodológicas do que propriamente em seu aprofundamento. Além disso, o questionamento central, apresentado inicialmente pelos coordenadores desse GDP aos participantes - Em meio à multiplicidade de abordagens metodológicas, quais seriam as formas investigativas reconhecidas nesse campo (ou área) acadêmico e investigativo da educação e como essas formas se organizariam e se comportariam nesse campo? - foi superficialmente tratado pelo grupo, pela falta de tempo para esse aprofundamento e de experiência do grupo participante nesse campo de pesquisa. 
De qualquer modo, a produção textual dos coordenadores, que traz as reflexões a partir dessa experiência, oferece contribuições para a área de pesquisa em questão, destacando o cenário da multirreferencialidade, das discussões decorrentes sobre a identidade do campo da pesquisa em EA e da pesquisa voltada para a transformação social, as quais merecerão maior aprofundamento em GDPs futuros. Nesse sentido, naquele evento optou-se pela continuidade do GDP Metodologia nos eventos posteriores, a fim de ampliar a participação, nesse GDP, de pesquisadores que se interessassem pelo aprofundamento das questões metodológicas abordadas, e, também, daqueles interessados em trazer novas questões que pudessem dinamizar esse debate.

Tozoni-Reis e Souza (2014), na coordenação da segunda edição do GDP Metodologia (VII EPEA, 2013), partiram de um levantamento, realizado anteriormente, sobre o tratamento dado às questões metodológicas nos trabalhos de pesquisa em educação ambiental apresentados nas seis edições anteriores do EPEA (2001, 2003, 2005, 2007, 2009 e 2011). Verificou-se que a maioria desses trabalhos examinados (339) anunciava a metodologia de pesquisa empregada, mas que um número significativo desses, não a anunciava (74), ou apresentava essa questão de forma bastante confusa (68), não permitindo aos coordenadores traçar um quadro claro em relação às opções metodológicas daqueles autores.

Dentre aqueles que anunciavam a metodologia empregada, a maioria (207) o fazia de forma essencialmente técnica, descritiva, limitada à apresentação dos procedimentos de pesquisa desvinculados de um aprofundamento teórico, reduzindo, muitas vezes, questões metodológicas aos procedimentos técnicos de pesquisa, o que denotava uma fragmentação entre a discussão metodológica e a discussão epistemológica. Além disso, verificou-se, nesses trabalhos, que as questões metodológicas da pesquisa eram confundidas com as questões metodológicas da ação educativa ambiental, o que apontava uma incompreensão no grupo acerca do que seria uma pesquisa em EA. Apesar disso, havia uma propensão entre os participantes que preconizava o reconhecimento da pesquisa qualitativa como a principal abordagem e a importância da diversidade de perspectivas metodológicas nesse campo de pesquisa, entrando em contradição com a tendência tecnicista em relação às metodologias empregadas.

Tais resultados desse levantamento inicial foram o ponto de partida para as discussões realizadas no presente GDP. Diante disso, o grupo considerou que a busca de um consenso com relação às questões metodológicas não seria necessária nem desejada, já que essa discussão se daria num plano de respeito à diversidade dos referenciais teóricos e metodológicos. Tentativas de superação da tendência de tratar a metodologia da pesquisa meramente como uma técnica, e para compreender o que seria uma pesquisa em EA, foram realizadas pelas coordenadoras durante essas discussões, buscando articular as questões metodológicas com as de epistemologia da pesquisa em EA. Como encaminhamento para essa questão, concluíram afirmando a necessidade de propostas de estratégias formativas para os pesquisadores iniciantes e de pesquisas nessa linha voltadas para a EA:

Para isso, consideramos que é urgente e necessária, a produção de estudos epistemológicos, por parte dos pesquisadores, que se dediquem também às questões metodológicas, assim como, do ponto de vista mais prático e operacional, articular, nos EPEAs, os GDPs de Questões Metodológicas e Questões Epistemológicas. Se considerarmos que, do ponto de vista da produção de conhecimentos, a episteme é um atributo eminentemente qualitativo, ele precede, em ordem e importância, os aspectos metodológicos do processo científico, e para nós, na educação ambiental, além da discussão epistemológica da educação e da ciência, a epistemologia ambiental tem espaço (TOZONI-REIS; SOUZA, 2014, p. 141).

Assim como na edição anterior, nesse GDP Metodologia do VII EPEA, as expectativas quanto à ampliação da representatividade de pesquisadores participantes, bem 
como a de uma discussão mais aprofundada sobre questões metodológicas no interior desse GDP, não foram correspondidas.

Tozoni-Reis e Kawasaki (2016), na coordenação da terceira edição do GDP Metodologia (VIII EPEA, 2015), encontraram um cenário bastante parecido ao das demais edições. O desejo de ampliar o número de participantes inscritos e de manter a vinculação dos participantes de edições anteriores a esse GDP, para consolidá-lo como um espaço permanente de discussões, acumulando conhecimentos e discussões sobre essa temática, foi parcialmente realizado. A expectativa de que esse tema fosse um assunto de preocupação dos pesquisadores não foi confirmada pela baixa procura dos participantes a esse GDP, que, na referida edição, foi inferior em relação às edições anteriores.

Apesar disso, observou-se que, dos oito participantes, três já tinham participado desse mesmo GDP na edição anterior, o que é um indicador importante para nossas expectativas de continuidade das discussões. As motivações dos participantes para participação nesse GDP foram similares às das edições anteriores, ou seja, a partir do reconhecimento da importância da metodologia como espinha dorsal da pesquisa e os caminhos metodológicos como desafio para o pesquisador, os participantes estavam à busca de um caminho metodológico ou um método/técnica específico para as suas pesquisas. Mais uma vez, evidenciou-se, no grupo, um discurso destacando a tendência majoritária da abordagem qualitativa na pesquisa e de sua relevância no cenário da pesquisa em EA e, particularmente nessa edição, destacou-se uma tendência crescente e predominante das perspectivas críticas, das modalidades de pesquisa de campo e das entrevistas como técnicas de pesquisa.

Nesse cenário, houve um destaque especial às metodologias de pesquisa participativas voltadas para a transformação social. Dois problemas evidenciados nos GDPs anteriores persistiram nessa edição: a descrição exaustiva de técnicas de coleta de dados da pesquisa, sem uma discussão teórica e epistemológica, e a confusão entre metodologia de pesquisa e metodologia de ensino/educacional/ação pedagógica, já que, ao abordarem a metodologia da pesquisa tendiam a uma descrição das ações pedagógicas em educação ambiental, detalhando a metodologia educativa e não a sua dimensão de pesquisa. $\mathrm{E}$

Entretanto, as discussões em torno dessas questões não caminharam, pois o grupo direcionou seu interesse para duas abordagens bastante correntes no contexto atual da pesquisa em EA: o materialismo histórico dialético como referencial teórico e metodológico, em virtude da forte preocupação com uma pesquisa voltada para a transformação social, e os estudos do tipo estado da arte, que, na visão dos participantes, tais estudos vêm crescendo e tomando forma nesse campo do conhecimento. Todavia, as discussões em torno dessas abordagens também não caminharam no grupo, já que deram lugar a uma espécie de aula sobre esses assuntos.

Nesse último encontro do GDP Metodologia (IX EPEA, 2017), verificou-se que os problemas elencados até então, ainda persistiam. Para além disso, vale a pena destacar, aqui, a presença significativa de pesquisas que apresentam como tema central os Desastres Ambientais e a EA, que, segundo seus autores, alinham-se às perspectivas teóricometodológicas da Psicologia das Emergências e da Metodologia do Desastre, as quais visam aplicação nas áreas de risco, como medidas de prevenção e atuação pós-desastres ambientais. Nessas, atrelam-se as perspectivas críticas da EA e a pesquisas participativas ou pesquisasação, em uma abordagem qualitativa da pesquisa educacional. Todavia, as discussões em torno delas incorreram nos mesmos equívocos já cometidos anteriormente, como a confusão entre metodologia da pesquisa e metodologia da ação pedagógica, já que, a preocupação maior estava voltada para a elaboração de instrumentos que permitissem diagnosticar e solucionar os conflitos e problemas socioambientais envolvidos nos desastres ambientais, sendo esses entendidos como instrumentos de pesquisa e não da ação. 
Em virtude de um cenário no qual esses problemas eram recorrentes, passou-se a aventar a possibilidade do GDP Metodologia voltar a integrar o GDP Epistemologia. Entretanto, esses mesmos problemas colocaram-nos desafios importantes na tentativa de superá-los. Independentemente do caminho a ser tomado - se a de um GDP específico para a discussão de aspectos metodológicos ou a volta à proposta inicial de um único GDP para a discussão de questões epistemológicas e metodológicas, o importante é que o debate continue. E é nessa perspectiva que destacamos uma tendência importante nessas discussões, que permitiu avançar nos debates.

\section{A busca pela transformação social como questão central das perspectivas teórico- metodológicas da pesquisa em EA}

Dentre as questões postas nesses relatos dos GDPs Metodologia, a tendência a atrelar as escolhas metodológicas dos investigadores a uma pesquisa voltada para a transformação social apresenta-se como questão central para as discussões em torno das perspectivas teóricometodológicas da pesquisa em EA. O direcionamento para uma pesquisa voltada para a transformação social não se coloca, no caso, apenas para questionar a realidade ou como questão de fundo dessas pesquisas, mas como uma importante meta da pesquisa, buscando estabelecer relações diretas entre as pesquisas em EA e os processos de transformação social. E é na esteira dessa tendência, que se atrelam, fortemente, as perspectivas críticas da EA e as metodologias de pesquisa participativas, principalmente as pesquisas-ação ou intervenção, como as abordagens metodológicas que responderiam de forma mais adequada às demandas dessa transformação social. Certamente, tal perspectiva traz implicações para esse cenário, as quais vale a pena discutirmos.

Carvalho (2016), ao apontar possíveis agendas e demandas que poderiam ser vistas como pertinentes para o campo da pesquisa em EA, já havia nos alertado sobre essa tendência. Ao tentar traçar o perfil e a identidade do campo da pesquisa em EA, o qual considerava estar em uma condição heterônoma, e tendo como referência os textos que fazem os relatos dos trabalhos realizados pelos GDP, o autor buscou a construção discursiva do campo da pesquisa em EA, por meio de alguns elementos como parte de um processo de construção de sentidos sobre a realidade, sobre a temática ambiental e sobre a perspectiva da EA e da pesquisa em EA. Nessa busca, deparou-se com uma diversidade de perspectivas teórico-metodológicas, fruto de um campo de pesquisa complexo e interdisciplinar, que, se por um lado é saudável para esse campo e para práticas democráticas, por outro, implica em uma produção acadêmica ainda bastante aberta, com vários atravessamentos e um baixo perfil de definição.

Tal perspectiva trouxe para Carvalho (2016, embasado em PAYNE, 2009) uma preocupação quanto ao significado histórico e valor estratégico do campo, levando a questionar as implicações dessa diversidade de perspectivas em EA para o desenvolvimento da pesquisa na área, para a compreensão e desenvolvimento das práticas de EA e para a construção de sua identidade, credibilidade social e papel político. Foi em meio a essa multiplicidade de perspectivas que o autor supracitado identificou uma tendência marcante, na qual encontrou uma forte relação entre a(s) escolha(s) metodológica(s) dos pesquisadores e uma pesquisa voltada para a transformação social:

É interessante observar que, muitas das escolhas quanto aos procedimentos metodológicos a serem adotados pelos investigadores, têm como justificativa o compromisso político e a intenção explícita de associação entre a pesquisa que se pretende desenvolver e os processos de transformação de uma determinada realidade (CARVALHO, 2016, p.156). 
Exemplos que ilustram essa tendência podem ser encontrados em pesquisas datadas nos primórdios dos EPEAs, como é o caso de Robottom (2006) que, ao ilustrar a complexidade e a contextualização das questões ambientais como conteúdos para a EA, descreve o desenvolvimento de projetos ambientais comunitários em dois locais distintos, para discutir aspectos epistemológicos e metodológicos da pesquisa participante em EA.

Igualmente, Copello (2006), ao propor a discussão dos fundamentos teóricos e metodológicos das pesquisas de EA relacionados à questão da ambientalização da escola, destaca, como uma das metas da pesquisa, a capacitação da escola para a ação, por meio de comunidades de aprendizagem; por sua vez, Loureiro (2008), ao coordenar o GDP Pesquisa em EA e Movimentos Sociais, reafirma a relevância de pesquisas acadêmicas voltadas para a questão da militância nos movimentos sociais e que promovam estudos que reconheçam a importância de tal relação no contexto histórico e sociopolítico contemporâneo.

Porém, essa tendência a atrelar as escolhas metodológicas dos investigadores, nesse caso, as perspectivas críticas da EA e as metodologias de pesquisa participativas, à pesquisa em EA voltada para a transformação social, traz algumas implicações. Uma delas se refere ao fato de que a perspectiva crítica é quase um pensamento hegemônico nesse contexto, trazendo, por vezes, adesões acríticas e pouco amparadas do ponto de vista epistemológico.

Nessa direção, Freitas e Oliveira (2006), ao analisarem os relatos de pesquisa selecionados para apresentação no I EPEA (2001), no tocante às suas perspectivas metodológicas, concluíram que muitos deles trazem pouco amparo teórico, inclusive aqueles que se situam na perspectiva crítica da EA. Em muitos desses relatos, as autoras depararam-se com um painel de opiniões de diferentes autores sobre o que seria a crise ambiental e seus desdobramentos, expressando a forma crítica com que esses se colocavam diante desse cenário, mas sem um arcabouço teórico que permitisse compreendê-los para além desse quadro opinativo.

Silva (2015) e Pedroso (2017), ao investigarem a perspectiva crítica da EA nas pesquisas em EA, encontraram trabalhos que se definiam como alinhados a uma perspectiva crítica apenas por oposição ao tradicional ou ao positivismo, caindo em uma negação indeterminada, que não permitia entender $\mathrm{o}(\mathrm{s}) \mathrm{seu}(\mathrm{s})$ significado(s) teóricos e epistemológicos. Para Trein (2012), a simples denominação crítica traz poucas pistas acerca do significado dessas pesquisas, levando-a a questionar, de forma instigadora, "crítica de $q u \hat{e}$ ?". Para Cavalari e Trein (2016), essa concepção que se autodenomina crítica não é suficientemente explicitada quanto à sua vertente epistemológica: A EA crítica vem de onde, da educação, da teoria crítica? Como as epistemologias críticas se materializam nas pesquisas em EA? Que autores/aportes/de onde falam esses autores?

Mesmo se considerarmos as perspectivas críticas que têm como base a Teoria Crítica, elas não são suficientes para dar respostas a todas as demandas colocadas pela multiplicidade de questões, campos do conhecimento e de perspectivas teórico-metodológicas presentes, tanto no campo pedagógico da EA como no campo da pesquisa em EA. Burnham (2006), ao apresentar as diferentes bases socioculturais e político-epistemológicas para a pesquisa na área de EA, já apontava a pluralidade da educação ambiental como alternativa viável para a superação da acelerada fragmentação do conhecimento e o crescimento de espaços sociais /de aprendizagem na sociedade. Perspectivas para além das críticas, as pós-críticas, as pósmodernas e outras, em uma gama infinita de abordagens epistemológicas e metodológicas, se apresentam nesse cenário, buscando responder às diferentes facetas da complexidade que representa a temática ambiental nos processos educativos.

A outra se refere à tendência das pesquisas voltadas à transformação social buscarem, nas metodologias de pesquisa participativas, respostas tanto para o campo pedagógico da EA como para o campo da pesquisa em EA. Nesse cenário, as metodologias de pesquisa 
participativas, que partem do princípio da relação entre pesquisa e intervenção, são consideradas as abordagens metodológicas mais coerentes com o empoderamento dos atores sociais envolvidos no processo e pesquisas relacionadas às práticas educacionais. Todavia, conforme já apontado por Tozoni-Reis e Souza (2014) e Tozoni-Reis e Kawasaki (2016) há, nas discussões desenvolvidas nos GDPs Metodologia, uma confusão entre metodologia da pesquisa e ação pedagógica, não distinguindo o que é uma e outra.

As autoras em tela (TOZONI-REIS; SOUZA, 2014; TOZONI-REIS; KAWASAKI, 2016) explicitam que essa confusão remete a um problema mais grave, que revela uma incompreensão acerca do próprio objeto de estudo da pesquisa em EA. A busca por métodos/técnicas de pesquisa, limitada à apresentação dos procedimentos de pesquisa desvinculados de um aprofundamento teórico representa, também, para essas autoras, um outro problema, pois remete à uma fragmentação entre a discussão metodológica e a discussão epistemológica.

Para Carvalho (2016), a perspectiva pragmática e a tendência imediatista percebida em muitas das investigações no campo da pesquisa em EA, no Brasil, implicam em um tratamento simplista na relação entre pesquisa e ação no campo da pesquisa em educação. A necessidade de transformação da sociedade, como meta a ser alcançada pela pesquisa, levando diretamente à projeção de uma realidade desejada, vem promover, segundo Freitas e Oliveira (2006), um descuido dos aspectos científicos e acadêmicos e da criticidade, necessários em termos de reflexão teórica sobre o tema, como se a relevância social da pesquisa por si justificasse a falta de clareza na esfera do conhecimento sobre aquela dada realidade.

De forma que, para Freitas e Oliveira (2006) a pesquisa em EA precisa ser vista como problematizável, requerendo deliberação e crítica, configurando uma postura desejável e coerente com um paradigma interpretativo/crítico de produção de conhecimento. É preciso, também, que essa pesquisa se desloque do campo da experiência propriamente dita, superando o fascínio da ação, para aportar no campo da produção acadêmica. Para Carvalho (2016), é preciso ter cuidados ao considerar essas abordagens metodológicas em processos de produção do conhecimento, para que essas pesquisas não se restrinjam apenas às ações de intervenção, associando, aos dados empíricos, o processo reflexivo e interpretação à luz das teorias que possam informar os processos de produção do conhecimento.

Nesse sentido, Tozoni-Reis (2007) propõe-se a analisar e discutir os compromissos e desafios das pesquisas participativas, buscando consolidar a pesquisa-ação-participativa em EA, tanto como uma forma metodológica de produzir coletivamente conhecimentos pedagógicos, como também, de a universidade atuar junto à comunidade, respondendo às suas necessidades de formação humana. Em um segundo artigo, Tozoni-Reis (2008) traz reflexões sobre a pesquisa-ação em EA, apontando suas questões centrais, características, limites e perspectivas para essa metodologia de pesquisa em EA.

\section{Para além dessas questões, a perspectiva de uma pesquisa subversiva em EA}

A reflexão sobre os relatos das experiências vivenciadas nas discussões nos GDP Metodologia trouxe-nos indicativos importantes para a continuidade das discussões metodológicas na pesquisa em EA, seja em um GDP específico ou não.

Em um campo onde a pesquisa voltada para a transformação social possui uma posição central, na qual a questão da militância e da ação de um sujeito ecológico (CARVALHO, 2016) se coloca, lado a lado, com a pesquisa e os pesquisadores, cujo papel passa a ser concebido como prática social, o enfrentamento da questão teoria-prática na pesquisa em EA passa a se colocar na ordem do dia. 
Recentemente, em uma palestra proferida no IX EPEA (2017), Phillipe Layrargues nos colocou diante de uma proposta instigadora em relação ao papel da EA no mundo de hoje, trazendo, consequentemente, reflexões importantes para o campo da pesquisa em EA.

Em um cenário mundial de avanço do neoliberalismo e da lógica mercantilista em todos os setores sociais e da acelerada degradação ambiental, Layrargues veio nos propor, de forma corajosa, uma Educação Ambiental subversiva, em oposição a uma Educação Ambiental subserviente. Para ele, a Educação Ambiental brasileira tornou-se um aparelho ideológico de Estado, obediente à reprodução social da formação capitalista e subserviente à sociabilidade do mercado:

Essa Educação Ambiental reprodutivista passa a controlar seletivamente a mensagem que flui pelo sistema político da Educação Ambiental, bem como pela Comunicação Ambiental midiática em geral, para todos os espaços escolares e não escolarizados, difundindo orientações precisas sobre o pensar e fazer as práticas pedagógicas vinculadas à questão ambiental, alinhadas à perspectiva desenvolvimentista do ambientalismo de mercado. Ao mesmo tempo, impede a veiculação de mensagens de natureza subversiva que eventualmente ofereçam resistência ou ameaça à ordem social capitalista. Em nome da salvação da natureza, difunde-se a propaganda doutrinadora do capital e do apaziguamento social. Assim feita essa associação subliminar, o caminho da salvação da natureza necessariamente passa pelo mercado. Exercendo seu poder de controle seletivo sobre a mensagem, essa Educação Ambiental reprodutivista conquista hegemonia quando dissemina consensos absolutos doutrinadores que giram em torno da difusão exclusiva da agenda positiva, em torno de uma pauta pacificada dos 'bons exemplos' ou das 'boas práticas' inspiradoras para pavimentar o caminho da sustentabilidade pelo cidadão responsável; enquanto necessariamente omite a pauta negativa, ocultando os elementos estruturais da insustentabilidade inerente à lógica do capitalismo (LAYRARGUES, 2018, p.1-2).

E, por isso, busca recuperar o sentido contestatório e subversivo que foi subtraído da Educação Ambiental brasileira, afirmando que, se o papel da Educação Ambiental reprodutivista é o silenciamento das contradições do capital:

[...] então o debate político-pedagógico da Educação Ambiental Crítica necessariamente passa pela revelação e exposição daquilo que é ocultado, para recuperar o sentido profundo do 'empoderamento': o poder subversivo necessário à transformação social. O esforço decisivo que caracteriza a Educação Ambiental Crítica e anticapitalista está na revelação daquilo que a Educação Ambiental reprodutivista e capitalista se empenha em ocultar, como condição para recuperar o potencial contestatório sacrificado pelo silenciamento do debate ecopolítico nas práticas conservadoras da Educação Ambiental (LAYRARGUES, 2018, p.4-5).

Em suma, para esse autor, não basta apenas nutrir o ecologismo sem, também, impedir o avanço do antiecologismo: "A superação da insustentabilidade inexoravelmente passa pela dialética, só se faz com a luta contra o antagônico da sustentabilidade, mas para que isso ocorra, é necessário recuperar o sentido contestatório e subversivo que foi subtraído da Educação Ambiental brasileira (LAYRARGUES, 2018, p.5).

Em um movimento sintonizado com essa proposta, Carlos Rodrigues Brandão (apud LIMA; RODRIGUES, 2007), em uma palestra proferida no IX Fórum Brasileiro de EA, Universidade do Vale do Itajaí/Campus Balneário Camboriú, 2017, nos colocou diante de uma perspectiva de uma pesquisa militante para o campo da EA. Lima e Rodrigues (2007), ao relatarem uma entrevista feita com Brandão, em um artigo intitulado Antropologia Militante, explicitaram o que Brandão definiu, não tanto como uma antropologia aplicada, mas uma antropologia em serviço, ou uma antropologia participante, que permitiu introduzir a perspectiva de uma pesquisa militante. Pesquisa esta que buscaria uma adesão a 
certos valores sociais progressistas, comprometidos com a qualidade de vida e a perspectiva cidadã que norteariam a construção desse conhecimento "militante".

Jaumont e Varella (2016), ao partirem da premissa de que a produção de conhecimentos e o desenvolvimento científico não estão dissociados dos acontecimentos societários, mas, pelo contrário, são partes constituintes dos mesmos, introduzem uma perspectiva crítica e militante na produção de conhecimento. Para tanto, sistematizam elementos convergentes de diversas experiências do campo, que apontam para uma concepção teórico-metodológica assentada nessa perspectiva, que não é somente possível, mas necessária e urgente no cenário atual:

Conhecer a realidade é uma exigência para transformá-la e os setores populares e suas organizações, se pretendem caminhar para uma sociedade mais justa e igualitária, precisarão conformar um pensamento crítico potente, uma práxis transformadora e um arcabouço teórico-metodológico adequado para viabilizar a socialização deste processo para amplas camadas das sociedades latino-americanas. As e os pesquisadores possuem um papel importante neste caminho ao, superando o mito da neutralidade da ciência moderna, se comprometer na construção desta valiosíssima contribuição (JAUMONT; VARELLA, 2016, p.418).

É nesse contexto, em que a ciência é concebida como um importante meio para contribuir para o processo de transformação social, que se inscrevem as metodologias de pesquisa participativas e, agora, a pesquisa militante. E, quem sabe, assim como Layrargues (2018) trouxe para o campo da EA uma EA subversiva, porque não a possibilidade de uma pesquisa subversiva, na qual a produção do conhecimento possa, também, fazer frente ao avanço desse quadro socioambiental perverso e de uma ciência reformista, que imbuída do caráter da (falsa) neutralidade, oculta a problematização do contraditório nesse cenário para assegurar a continuidade de uma ciência normal.

Propostas desafiadoras como essas, certamente, contribuem para adensar nossas discussões sobre as relações entre teoria e prática nas perspectivas teórico-metodológicas da pesquisa em EA. Independentemente da área ou da corrente teórica às quais essas discussões se filiam, ou da finalidade que se busca com a pesquisa nesse campo do conhecimento, o importante é buscar uma relação dialética entre teoria e prática, onde a indissociabilidade, entre os modos de habitar o mundo e o de conhecer o mundo, esteja garantida. Afinal de contas, conhecer é, ao mesmo tempo, um processo de objetivação e de subjetivação, ou seja, conhecer é personificar e, também, tomar o ponto de vista do objeto.

E o epistemológico é tão político quanto as ações políticas, pois segundo Trein (2012), o embate teórico tem sido necessário caso queiramos alimentar expectativas sobre a possibilidade de se propor alternativas que possam ser, de fato, transformadoras, em uma busca de articulações entre ontologia (engajamento social), epistemologia e metodologia que explicita, por meio do conhecimento produzido, os interesses político-ideológicos implícitos nela.

\section{Referências}

BURNHAM, T.F. Pesquisa multirreferencial em educação ambiental: bases sócio-culturais-políticoepistemológicas. Pesquisa em Educação Ambiental, Rio Claro, v. 1, n.1, p. 73-92, jul/dez. 2006.

CARVALHO, L.M. Demandas e agendas da Pesquisa em Educação Ambiental: sentidos construídos a partir dos relatos dos Grupos de Discussão de Pesquisa em Educação Ambiental (GDPS-EPEAS). Pesquisa em Educação Ambiental, Rio Claro, v. 11, n.2, p. 146-167, jul/dez. 2016. 
CAVALARI, R.M.F.; TREIN, E.S. Pesquisa em Educação Ambiental e Questões Epistemológicas: a necessidade da continuidade do debate. Pesquisa em Educação Ambiental, Rio Claro, v. 11, n. 2, p. 83-96, jul/dez.2016.

COPELLO, M.I. Fundamentos teóricos e metodológicos de pesquisas sobre ambientalização da escola. Pesquisa em Educação Ambiental, Rio Claro, v. 1, n.1, p. 93-110, jul/dez. 2006.

FERNANDES, J. A. B.; KAWASAKI, C. S. A pesquisa em educação ambiental e questões metodológicas: relato do grupo de discussão de pesquisa no VI EPEA. Pesquisa em Educação Ambiental, Rio Claro, v. 7, n. 2, p.91-103, jul/dez. 2012

FREITAS, D.; OLIVEIRA, H.T. Pesquisa em Educação Ambiental: um panorama de suas tendências metodológicas. Pesquisa em Educação Ambiental, Rio Claro, v.1, n.1, p. 175-191, jul/dez. 2006.

JAUMONT, J.; VARELLA, R. V. S. A Pesquisa Militante na América Latina: trajetória, caminhos e possibilidades. Direito e Práxis, Rio de Janeiro, v. 07, n. 13, p. 414-464, 2016.

LAYRARGUES, P.P. Educação Ambiental nas sociedades capitalistas. Novamerica, Rio de Janeiro, n. 157, p. 24-30, 2018.

LIMA, R.; RODRIGUES, C.M.C. Uma Antropologia Militante. Sociedade e Cultura, Goiânia, v. 10, n. 1, p. 145-149, jan/jun. 2007.

LOUREIRO, C. F. B. Educação Ambiental e Movimentos Sociais: reflexões e questões levantadas no GDP. Pesquisa em Educação Ambiental, Rio Claro, v. 3, n. 1, p. 187-201, jan/jun. 2008.

PEDROSO, E. M. M. M. A abordagem da práxis educativa em dissertações e teses em Educação Ambiental Crítica. 2017. Dissertação (Mestrado em Educação) - Programa de Pós-Graduação em Educação da FFCLRP/USP, Ribeirão Preto, 2017.

ROBOTTOM, I. Participatory Research in EE: Some issues of epistemology and methodology Pesquisa em Educação Ambiental, Rio Claro, v. 1, n.1, p. 11-25, jul/dez. 2006.

SILVA, M.C.B. A perspectiva crítica nas pesquisas em Educação Ambiental. 2015. Dissertação (Mestrado em Educação) - Programa de Pós-Graduação em Educação da FFCLRP/USP, Ribeirão Preto, 2015.

TOZONI-REIS, M. F. C. A construção coletiva do conhecimento e a pesquisa-ação participativa: compromissos e desafios. Pesquisa em Educação Ambiental, Rio Claro, v. 2, n.2, p. 89-107, jul/dez. 2007.

TOZONI-REIS, M. F. C. Pesquisa-ação em Educação Ambiental. Pesquisa em Educação Ambiental, Rio Claro, v. 3, n. 1, p. 155-169, jan/jun. 2008.

TOZONI-REIS, M. F. C.; SOUZA, D. C. Pesquisa em Educação Ambiental e Questões Metodológicas: uma discussão coletiva. Pesquisa em Educação Ambiental, Rio Claro, v. 9, n. 1, p. 133-143, jan/jun. 2014.

TOZONI-REIS, M. F. C.; KAWASAKI, C. S. Questões Metodológicas na Pesquisa em Educação Ambiental: necessidades e desafios. Pesquisa em Educação Ambiental, Rio Claro, v. 11, n. 2, p. 97104, jul/dez. 2016.

TREIN, E. S. A Educação Ambiental Crítica: crítica de quê? Revista Contemporânea de Educação, Rio de Janeiro, v.7, n. 14, p.304-318, agosto/dezembro de 2012. 